\title{
Localization of new peptidoglycan at poles in Bacillus mycoides, a member of the Bacillus cereus group
}

\author{
Luana Turchi · Tiziana Santini · Elena Beccari • \\ Carmen Di Franco
}

Received: 6 March 2012 /Revised: 28 May 2012 / Accepted: 6 June 2012/Published online: 8 July 2012

(C) The Author(s) 2012. This article is published with open access at Springerlink.com

\begin{abstract}
Bacillus mycoides is a sporogenic Gram-positive soil bacillus of the B. cereus group. This bacillus, which forms hyphal colonies, is composed of cells connected in filaments that make up bundles and turn clock- or counterclockwise depending on the strain. A thick peptidoglycan wall gives the rod cells of these bacilli strength and shape. One approach used to study peptidoglycan neoformation in Gram positives exploits the binding properties of antibiotics such as vancomycin and ramoplanin to nascent peptidoglycan, whose localization in the cell is monitored by means of a fluorescent tag. When we treated B. mycoides strains with BODIPY-vancomycin, we found the expected accumulation of fluorescence at the midcell septa and localization along the cell sidewall in small foci distributed quite uniformly. Intense fluorescence was also observed at the poles of many cells, more clearly visible at the outer edges of the cell chains. The unusual abundance of peptidoglycan intermediates at the cell poles after cell separation suggests that the construction process
\end{abstract}

Communicated by Pierre Beguin.

L. Turchi · T. Santini - C. Di Franco

Dipartimento di Biologia e Biotecnologie "C. Darwin", Università Sapienza, Roma, P.le A. Moro 5, 00185 Rome, Italy

e-mail: luana.turchi@uniroma1.it

T. Santini

e-mail: tiziana.santini@uniroma1.it

C. Di Franco

e-mail: carmen.difranco@uniroma1.it

E. Beccari $(\bowtie)$

Istituto di Biologia e Patologia Molecolari IBPM-CNR,

Università Sapienza, Roma, P.le A. Moro 5, 00185 Rome, Italy

e-mail: elena.beccari@uniroma1.it of this structure is different from that of B. subtilis, in which the free poles are rarely reactive to vancomycin.

Keywords B. mycoides $\cdot$ B. cereus group · Cell wall · Peptidoglycan · Cell poles · Vancomycin staining

\section{Introduction}

The thick cell wall of Gram-positive bacilli contains several layers of peptidoglycan (PG), a unique giant polymer of glycan strands made of alternating $\mathrm{N}$-acetylglucosamine and $\mathrm{N}$-acetylmuramic acid, cross-linked by peptide bridges (Vollmer et al. 2008). The PG precursors are the lipid II GlcNAc-MurNAc-pentapeptides, linked to the membrane through the lipid anchor in the cellular sites of active PG synthesis (de Kruijff et al. 2008). The PG precursors and the pentapeptides of the nascent glycan chains expose a free D-Ala-D-Ala group specifically bound by the antibiotic vancomycin. When linked to different fluorochromes, vancomycin can be used to label, and hence visually detect, the spatial pattern of new PG localization within the cell. This approach has been used to detect the sites of cell wall neoformation in B. subtilis (Daniel and Errington 2003; Tiyanont et al. 2006), though no such information is available for the numerous bacilli with a similar cell shape that constitute the B. cereus group (Guinebretiere et al. 2008).

B. mycoides is the member in this group that has received least attention because it is not as harmful to humans as B. anthracis and B. cereus or an insecticidal agent as $B$. thuringiensis. $B$. mycoides was first studied by the Russian naturalist Gause (1939), who investigated the genesis of the typical colonies of these soil bacilli, whose growth on agar plates forms an attractive rhizoidal shape 
resulting from cells connected at the poles that form long filaments resembling fungal hyphae, grouped in bundles curving to the right or to the left in different strains called dextral (DX) and sinistral (SIN) (Fig. 1 top panel). The strong cell-to-cell connections yield a stable network that favors interactions with other soil inhabitants, such as microbes, fungi and plant roots (Petersen et al. 1995; Kloepper et al. 2004).

We isolated wild-type strains of two types from the soil and collected mutants of the typical B. mycoides colony morphotype, all characterized by looser cell connections. These mutants fall within a few classes that progressively modify the colony chiral shape. The most divergent is the round and compact colony of SINett, a SIN-derived phenotypic mutant whose mutation has not been determined. Light microscopy analysis of colony growth on agar showed that the cell chains of SINett are those most frequently interrupted during multiplication on the Petri dish surface (Di Franco et al. 2002). In the present study, in which we bound fluorescent vancomycin (Van-BDP) to
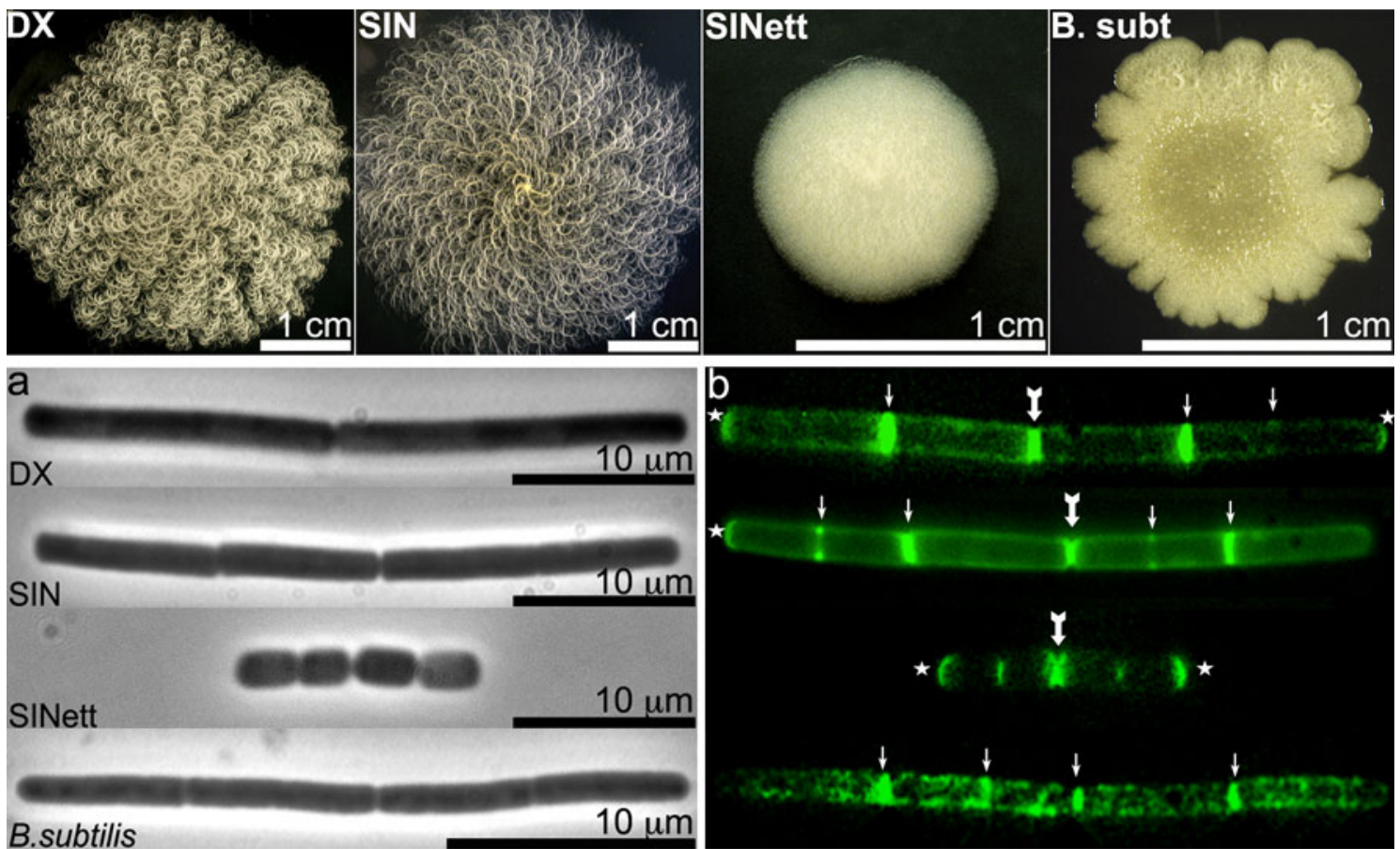

\section{B.subtilis}

$10 \mu \mathrm{m}$
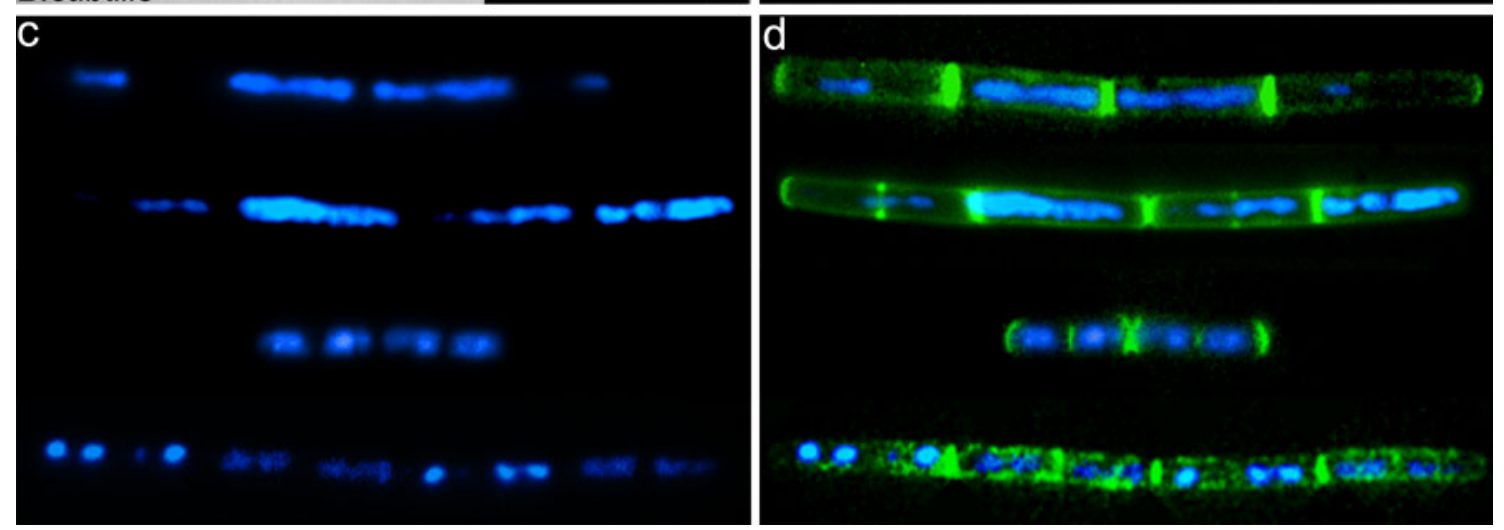

Fig. 1 Colony shape and cells of B. mycoides DX, SIN, SINett and $B$. subtilis 168. Top panel: colonies of B. mycoides DX, SIN and SINett were grown on TS agar for $72 \mathrm{~h}$ at $30{ }^{\circ} \mathrm{C}$, while $B$. subtilis colonies were grown at $37{ }^{\circ} \mathrm{C}$. Note the macroscopic hyphal pattern and the opposite direction of filament bundles in wild-type $B$. mycoides strains (EMBO Journal published this $B$. mycoides DX colony image on the cover of volume 28,16 Sept. 2009). Bottom panel: B. mycoides DX, SIN, SINett and B. subtilis 168 cells in the exponential growth phase were treated with Van-BDP/vancomycin to stain new PG and with DAPI to visualize nucleoids as described in "Materials and

methods". a Phase contrast images. b Van-BDP fluorescence: arrows point to septa, thick arrows to internal newly formed poles, stars to fluorescent free poles. Note that fluorescence along the lateral cell wall is localized in small foci in $B$. mycoides and in large foci in $B$. subtilis. The external poles of the $B$. mycoides filaments are often brightly fluorescent, while they are rarely decorated by Van-BDP in B. subtilis. c DAPI staining of nucleoids. See multiple nucleoids in DX and SIN cells. d Overlay of Van-BDP (green) and DAPI (blue). Images were merged using Adobe Photoshop version 7.0 
live cells, we found that $B$. mycoides is characterized by the frequent polar localization of the antibiotic. The poles most frequently fluorescent were those identified in strains that typically formed non-hyphal compact colonies.

\section{Materials and methods}

Bacterial strains and growth conditions

Bacillus mycoides strains DX and SIN are environmental laboratory stocks, while SINett is a spontaneous phenotypic SIN mutant (Di Franco et al. 2002). B. subtilis subsp subtilis 168 (BGSC 1A1) was obtained from the Bacillus Genetic Stock Center, Columbus, Ohio. Bacilli were all cultured in TS broth (Trypton Soya, Oxoid) and the colonies formed on $15 \mathrm{~g} / \mathrm{l}$ agar in TS. Growth temperature for B. subtilis was $37^{\circ} \mathrm{C}$. B. mycoides strains were grown at the optimal temperature of $30^{\circ} \mathrm{C}$, the duplication time being 25-30 min in these conditions. Overnight cultures were diluted about 100-fold in fresh medium and incubated 2-3 h so that cells could be collected in the exponential growth phase. Spores were prepared from old Petri dish cultures by vortexing strains in fresh TS broth and repeatedly discarding debris by centrifugation. The spore suspension was incubated in TS broth at $30{ }^{\circ} \mathrm{C}$ for $2-5 \mathrm{~h}$ until the majority of the spores germinated.

\section{Vancomycin staining}

The MIC of the DX and SIN B. mycoides strains was detected at $2 \mu \mathrm{g} / \mathrm{ml}$ for BODIPY-FL conjugate vancomycin (Van-BDP, Molecular Probes) and at $0.2 \mu \mathrm{g} / \mathrm{ml}$ for unlabeled vancomycin (Sigma) in TS. The concentrations normally used in this study, blocking growth of all the before mentioned strains, were $2 \mu \mathrm{g} / \mathrm{ml}$ Van-BDP plus $2 \mu \mathrm{g} / \mathrm{ml}$ unlabeled vancomycin for $10 \mathrm{~min}$ at $30{ }^{\circ} \mathrm{C}(B$. mycoides) and at $37^{\circ} \mathrm{C}$ (B. subtilis) in the dark. Live cells grown to the mid-exponential phase or newly produced from germinated spores were treated and then washed with fresh TS broth, loaded on polylysine-treated microscopic slides and mounted in Vectashield (Vector laboratories), with the DNA-dye DAPI (4', 6-diamidino-2-phenylindole) at a final concentration of $0.25 \mu \mathrm{g} / \mathrm{ml}$.

\section{Live-cell fluorescence microscopy}

Cells were examined with a Zeiss Axioplan microscope with an HBO $50 \mathrm{~W}$ mercury lamp for epifluorescence, equipped with a cooled charge-coupled device (Sensys). Greyscale digital images were collected separately with RS Image v1.9.2 software (Roper Scientific). CCD camera exposure times were set at Automatic Exposure: Intensity
Target of 1,000 pxl and Upper Limit of $4 \mathrm{~s}$. Images were converted to Photoshop vs 7.0 format (Adobe), pseudocolored and merged.

\section{Results}

Fluorescent vancomycin staining of $B$. mycoides

The distribution of PG precursors was analyzed in cells of the $B$. mycoides strains studied in our laboratory (Di Franco et al. 2002). We used the BODIPY derivative of the antibiotic vancomycin (Van-BDP), chosen on account of the small size of the fluorescent tag, which affords easier access to the cell wall D-Ala-D-Ala ligands and presents fewer aggregation problems than Van-FL (Tiyanont et al. 2006). The minimal inhibitory concentration of Van-BDP (MIC) on B. mycoides cells was found at $2 \mu \mathrm{g} / \mathrm{ml}$, while the concentration of unlabeled vancomycin required to interrupt growth was lower, that is approx. $0.2 \mu \mathrm{g} / \mathrm{ml}$. Staining of the cells was too faint when Van-BDP was used below the MIC. Increasing concentrations of Van-BDP were then tested, either alone or mixed with unlabeled vancomycin, which was reported to increase staining of the lateral cell wall in B. subtilis (Daniel and Errington 2003; Tiyanont et al. 2006). Addition of unlabeled vancomycin did not change the lateral wall fluorescence in B. mycoides, while it increased staining in B. subtilis as expected. The staining procedure thereafter routinely used a mixture $1: 1$ of Van-BDP and unlabeled vancomycin, both at $2 \mu \mathrm{g} / \mathrm{ml}$, which worked well for both B. mycoides and B. subtilis. The antibiotics, when above the MIC, blocked cell growth and revealed the instant pattern of $\mathrm{PG}$ precursors binding the fluorescent probe. The exposition period to Van-BDP was usually about $10 \mathrm{~min}$, but the cell decoration was not modified in experiments lasting from $1 \mathrm{~min}$ up to hours, the only consequence during long treatments being an increase in the number of cells that lost their cellular content and thus appeared as "ghosts". The staining of the sidewall, septa and poles remained similar even in the ghosts.

When we treated fresh unfixed cells of B. subtilis 168 and B. mycoides strains DX, SIN and SINett, the mutant with a non-hyphal colony (Fig. 1 top panel) with Van-BDP as described, fluorescence was very intense at midcell septa both in the B. mycoides strains and in B. subtilis 168 (Fig. 1b, arrows). Fluorescence was quite uniformly concentrated in small spots along the cylindrical cell body in B. mycoides, while B. subtilis 168 exhibited bright sidewall staining in large foci (Figs. 1, 2).

Unexpectedly, several B. mycoides cell poles displayed a consistent amount of fluorescence along the entire length of their curvature, while the poles in B. subtilis were generally unstained. Polar Van-BDP fluorescence was 


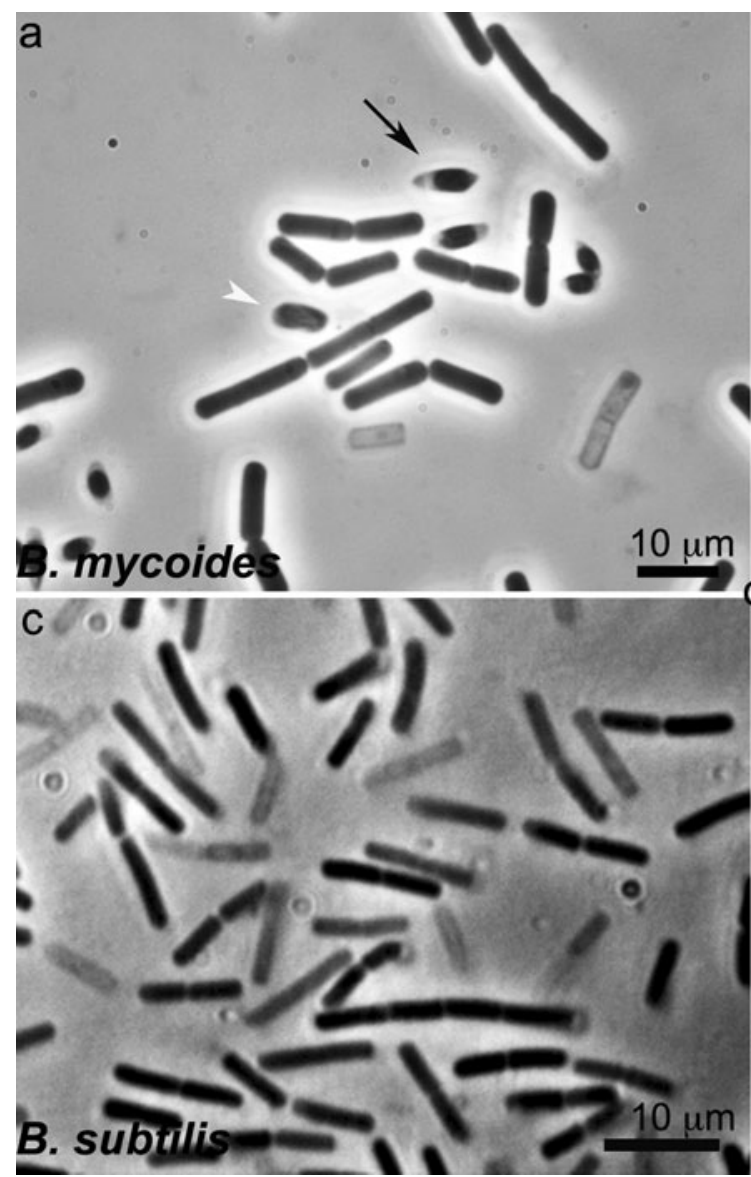

Fig. 2 View of B. mycoides SIN and B. subtilis cells from germinated spores. The short filaments arose from spores seeded in TS broth. After $4 \mathrm{~h}$ at $30{ }^{\circ} \mathrm{C}$ ( $\mathrm{SIN}$ ) and at $37{ }^{\circ} \mathrm{C}$ (B. subtilis), Van$\mathrm{BDP} / \mathrm{vancomycin}$ at $2 \mu \mathrm{g} / \mathrm{ml}$ each was added for $10 \mathrm{~min}$. a phase contrast and b Van-BDP fluorescence of B. mycoides SIN; c phase contrast and d Van-BDP fluorescence of B.subtilis 168. Note that the

observed at the edges between separate cells that were connected and formed filaments (Fig. 1b, thick arrows) and at the free poles of filament edges (Fig. 1b, stars). Polar labeling was obtained by treating cells from exponential vegetative cultures (Fig. 1) and from germinated spores (Fig. 2). In cultures initiated from germinated spores (Fig. 2), the short filaments were all composed of newborn cells, and the poles could not be mistaken as septa of broken cells as might occur in cultures of vegetative cells. When cells grown on agar were also analyzed, they yielded the same results.

The transition from the midcell septum to the two new poles is a continuous process in dividing cells. The internal poles in a cell chain can then be easily confused with uncompleted septa. We thus stated the frequency of polar staining by Van-BDP considering in the statistics (Fig. 3) as bona fide poles only the free external poles of the cell chains.

Not all of the external free poles carried Van-BDP fluorescence. The frequencies were calculated as the

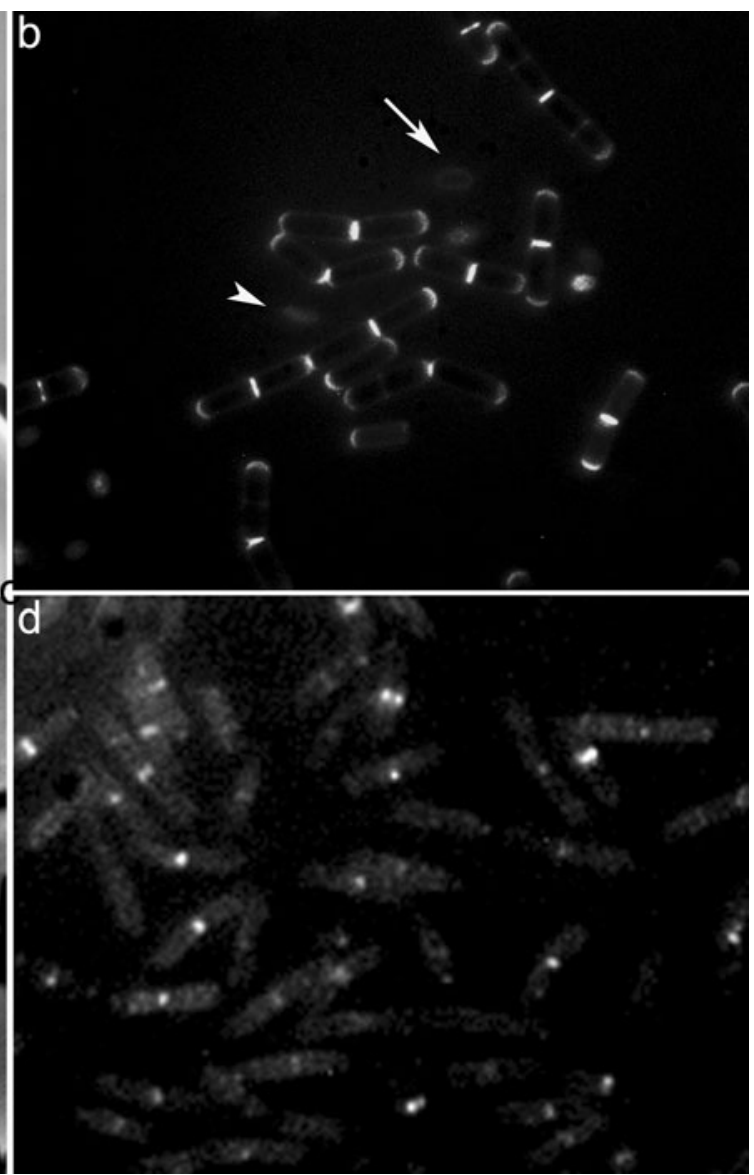

rod cells are mainly stained by Van-BDP at septa and poles in $B$. mycoides, and mainly at septa and along the lateral wall in large foci in B. subtilis. Some cells are "ghosts", stained nonetheless by VanBDP. The arrow points to a spore starting germination and the arrowhead to a spore in a more advanced germination stage

average of several experiments, taking into account the values from not less than 90 filaments considered in each observation. As shown in the histogram of Fig. 3, in the DX strain, $39 \%$ of the cell chains showed one of the two external poles stained by Van-BDP, $56 \%$ had both the external poles stained and only $5 \%$ of the chains did not show polar staining at all. In SIN, the values were: $27 \%$ of the chains had one pole stained, $69 \%$ had two poles stained and $4 \%$ no poles stained. Both DX and SIN are characterized by very long cell chains that form the typical hairy colony (Fig. 1 top). In SINett, with a round compact colony made up by shorter filaments, both poles were stained more frequently. The values were: $12 \%$ of the chains had one pole stained, $86 \%$ had both poles stained and $2 \%$ no poles stained. In $B$. subtilis 168 , we found instead that $96 \%$ of the chains had no poles stained. The latter finding is in agreement with classical experiments that indicate the polar regions of B. subtilis as relatively inert, with low wall turnover (Clarke-Sturman et al. 1989; Daniel and Errington 2003). 


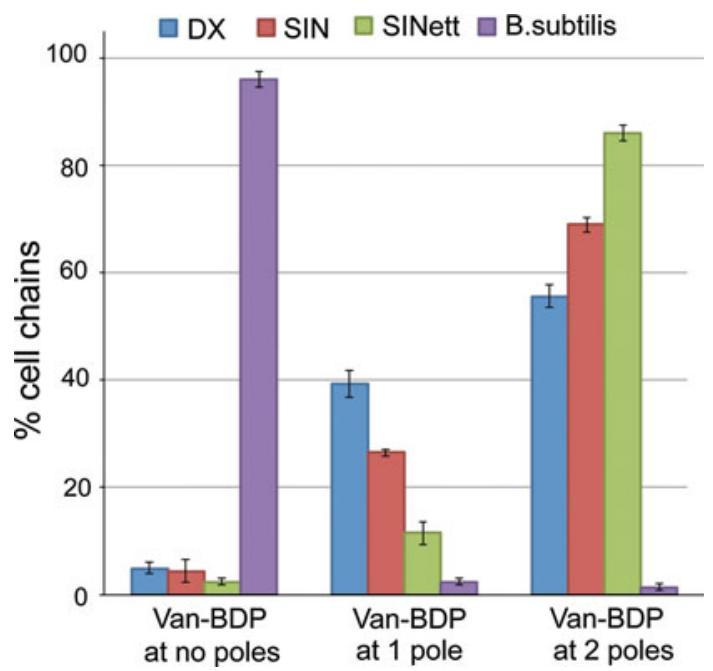

Fig. 3 Van-BDP at the poles in B. mycoides strains and in B. subtilis. The histogram shows the percentage of the cell chains that show at the free external poles no Van-BDP binding, binding to only one pole or to both poles as the average of at least 3 independent experiments. Error bars show standard deviations. The poles of $B$. subtilis are very rarely bound by Van-BDP. Among the B. mycoides strains, Van-BDP is found more frequently at both poles in the mutant SINett

In the same experiments, DAPI staining evidenced that septa did not form at any potential division site, as demonstrated by the fact that two or more nucleoids without intervening septa in DX and SIN filaments were not uncommon (Fig. 1c, d). In SINett, by contrast, nucleoid separation and positioning of septa coexisted, as also occurred in the B. subtilis sample.

\section{Discussion}

Vancomycin, the so-called last-resort drug for antibioticresistant infections, is a useful tool for detecting new PG location sites in the bacterial cell wall (Daniel and Errington 2003; Tiyanont et al. 2006). This antibiotic binds to the C-terminal D-Ala-D-Ala residues present in the pentapeptide of lipid II-linked disaccharides, the PG precursors, and in the un-crosslinked peptides of nascent peptidoglycan (Vollmer et al. 2008). When bound to a fluorescent tag, vancomycin decorates the cellular sites of massive PG synthesis, above all the division septa. It may also bind inside the old PG, where interpeptide bonds may not have been completed, leaving a free D-Ala-D-Ala group exposed, but the background in such cases is randomly distributed and not condensed into visible spots.

The localization of fluorescent vancomycin in fresh cells of $B$. mycoides strains revealed some characteristic features. The reactive PG along the cell sidewall, if compared with B. subtilis, was randomly distributed and formed smaller foci that do not appear to be arranged helically
(Daniel and Errington 2003, Carballido-Lopez 2006). Recently, the helical arrangement of new PG synthesis sites was not confirmed in B. subtilis following the introduction of a more sensitive analysis method. Total internal reflection fluorescence microscopy (TIRFM) was used to follow the movement inside the live cell of GFP-linked actin-like proteins and GFP proteins of the multienzyme complexes for PG synthesis, showing GFP-proteins moving in a circular motion along radial bands perpendicular to the cell length (Garner et al. 2011, Dominguez-Escobar et al. 2011). These observations are consistent with the model for peptidoglycan architecture proposed for B. subtilis on the basis of atomic force microscope imaging (Hayhurst et al. 2008). In the cell body of B. mycoides, where the sites of PG neosynthesis are quite uniformly distributed, the enzyme complexes might be located along thinner radial bands.

Another characteristic of B. mycoides and of other bacilli of the same group (preliminary data not shown) is the persistent Van-BDP fluorescence at several poles after cell separation, which is in contrast to the rarely observed reaction to vancomycin of the free poles in $B$ subtilis.

The possible reasons underlying polar labeling can as yet only be hypothesized. At the pole, after division and cell separation, new PG synthesis might continue, differently from B. subtilis, because it is required by a particular architecture of the pole.

Alternatively, no new PG synthesis is occurring, and polar labeling might be due exclusively to pools of free PG precursors, left over after the end of septation and slowly diluted away from the new pole. This explanation does not, however, hold for the polar staining observed in cells born from spores. Newly germinated 2-cell and 4-cell chains (see Fig. 2) have external poles that do not originate from a septation event but come directly from the spore and are, nonetheless, brightly labeled. Van-BDP fluorescence, which is low in non-germinated spores (see the spores indicated by the arrow and the arrowhead in Fig. 2), becomes intense at the poles, suggesting active recruitment of PG precursors at that location for new wall synthesis.

Active accumulation of PG precursors at a polar site may be required to prepare that precise cell edge for oriented cell multiplication (Dworkin 2009). When we observed growth on agar plates of the DX and SIN $B$. mycoides strains under the microscope, we noticed that the colonies extended in a centrifugal direction, mainly through multiplication of the cells at the filament edges. Polarized growth may thus be considered typical of these strains. Filament interruptions are likely to be downregulated in the hyphal strains like DX and SIN by growth inhibition at one cell pole, which would explain the higher number of cell chains with only one outer pole bound by Van-BDP compared to non-hyphal strains, that is the 
SINett mutant, which has both poles bound more frequently by Van-BDP (see histogram of Fig. 3). Nonpolarized but simultaneous growth at adjacent poles of two consecutive cells may determine tensions within a filament causing the cell chain interruptions observed during colony construction in SINett (Di Franco et al. 2002).

Our data, which are based on cytological observations, highlight some interesting features of the cell wall in $B$. mycoides, shared with other members of the B. cereus group. We cannot yet use the various DNA transformationbased molecular biology tools that have shed light over the years on numerous processes in model bacteria, because the environmental B. mycoides DX and SIN strains carry multiple restriction activities against exogenous DNA. The homogeneous distribution of vancomycin binding in members of the $B$. cereus group will, however, make it easier to investigate polar PG synthesis in strains that lend themselves to DNA transformation.

Acknowledgments This work was supported by the Italian Space Agency with ASI contract no. 1/R/290/02 and ASI-MoMa project 2006-2009. Institutional funds came from the CNR Istituto di Biologia e Patologia Molecolari IBPM. Science Faculty funds from the Sapienza University of Rome supported C.D.F. We thank EMBO Journal that published the image of the B. mycoides DX strain colony on the cover of volume 28, 16 Sept. 2009. We thank Fioretta Palombi for her helpful comments and advice on the imaging, and Giuseppe Pisaneschi for his valuable technical assistance.

Open Access This article is distributed under the terms of the Creative Commons Attribution License which permits any use, distribution, and reproduction in any medium, provided the original author(s) and the source are credited.

\section{References}

Carballido-Lopez R (2006) The bacterial actin-like cytoskeleton. Microbiol Mol Biol Rev 70:888-909

Clarke-Sturman AJ, Archibald AR, Hancock IC, Harwood CR, Merad T, Hobot JA (1989) Cell wall assembly in Bacillus subtilis: partial conservation of polar wall material and the effect of growth conditions on the pattern of incorporation of new material at the polar caps. J Gen Microbiol 135:657-665

Daniel RA, Errington J (2003) Control of cell morphogenesis in bacteria: two distinct ways to make a rod-shaped cell. Cell 119:767-776

de Kruijff B, van Dam V, Breukink E (2008) Lipid II: a central component in bacterial cell wall synthesis and a target for antibiotics. Prostaglandi Leukot Essent Fat Acids 79:117-121

Di Franco C, Beccari E, Santini T, Pisaneschi G, Tecce G (2002) Colony shape as a genetic trait in the pattern-forming Bacillus mycoides. BMC Microbiol 2:1-15

Dominguez-Escobar J, Chastanet A, Crevenna AH, Fromion V, Wedlich-Soldner R, Carballido-Lopez R (2011) Processive movement of MreB-associated cell wall biosynthetic complexes in bacteria. Science 333:225-228

Dworkin J (2009) Cellular polarity in prokaryotic organisms. Cold Spring Harb Perspect Biol 1:a003368

Garner EC, Bernard R, Wang W, Zhuang X, Rudner DZ, Mitchison T (2011) Coupled, circumferential motions of the cell wall synthesis machinery and MreB filaments in B. subtilis. Science 333:222-225

Gause GF (1939) Some physiological properties of dextral and of sinistral forms in Bacillus mycoides flügge. Biol Bull Woods Hole MA 76:448-465

Guinebretiere MH, Thompson FL, Sorokin A, Normand P, Dawyndt P, Ehling-Schulz M, Svensson B, Sanchis V, Nguyen-The C, Heyndrickx M, De Vos P (2008) Ecological diversification in the Bacillus cereus group. Environ Microbiol 10:851-865

Hayhurst EJ, Kailas L, Hobbs JK, Foster SJ (2008) Cell wall peptidoglycan architecture in Bacillus subtilis. Proc Natl Acad Sci USA 105:14603-14608

Kloepper JW, Ryu CM, Zhang S (2004) Induced systemic resistance and promotion of plant growth by Bacillus spp. Phytopathology 94(11):1259-1266

Petersen DJ, Shishido M, Holl FB, Chanway CP (1995) Use of species and strain-specific PCR primers for identification of conifer root-associated Bacillus spp. FEMS Microbiol Lett 133(1-2):71-76

Tiyanont K, Doan T, Lazarus MB, Fang X, Rudner DZ, Walker S (2006) Imaging peptidoglycan biosynthesis in Bacillus subtilis with fluorescent antibiotics. Proc Natl Acad Sci USA 103:11033-11038

Vollmer W, Blanot D, de Pedro MA (2008) Peptidoglycan structure and architecture. FEMS Microbiol Rev 32:149-167 